\title{
(6) OPEN ACCESS \\ Consensus statement on blocking the effects of interleukin- 6 and in particular by interleukin- 6 receptor inhibition in rheumatoid arthritis and other inflammatory conditions
}

\author{
Josef S Smolen, ${ }^{1,2}$ Monika M Schoels, ${ }^{2}$ Norihiro Nishimoto, ${ }^{3}$ Ferdinand C Breedveld, ${ }^{4}$ \\ Gerd R Burmester, ${ }^{5}$ Maxime Dougados, ${ }^{6}$ Paul Emery, ${ }^{7}$ Gianfranco Ferracciolii, \\ Cem Gabay, ${ }^{9}$ Allan Gibofsky, ${ }^{10}$ Juan Jesus Gomez-Reino, ${ }^{11}$ Graeme Jones, ${ }^{12}$ \\ Tore K Kvien, ${ }^{13}$ Miho Murakami, ${ }^{3}$ Neil Betteridge, ${ }_{1}^{14}$ Clifton 0 Bingham III, ${ }^{15}$ \\ Vivian Bykerk, ${ }^{9}$ Ernest $\mathrm{H}$ Choy, ${ }^{16}$ Bernard Combe, ${ }^{17}$ Maurizio Cutolo, ${ }^{18}$ \\ Winfried Graninger, ${ }^{19}$ Angel Lanas, ${ }^{20}$ Emilio Martin-Mola, ${ }^{21}$ Carlomaurizio Montecucco, ${ }^{22}$ \\ Mikkel Ostergaard, ${ }^{23}$ Karel Pavelka, ${ }^{24}$ Andrea Rubbert-Roth, ${ }^{25}$ Naveed Sattar, ${ }^{26}$ \\ Marieke Scholte-Voshaar, ${ }^{27}$ Yoshiya Tanaka, ${ }^{28}$ Michael Trauner, ${ }^{29}$ Gabriele Valentini, ${ }^{30}$ \\ Kevin L Winthrop, ${ }^{31}$ Maarten de Wit, ${ }^{32}$ Désirée van der Heijde ${ }^{4}$
}

For numbered affiliations see end of article.

\section{Correspondence to} Professor Josef S Smolen, Division of Rheumatology, Department of Medicine 3 , Medical University of Vienna Waehringer Guertel 18-20, Vienna A-1090, Austria; josef.smolen@wienkav.at: josef.smolen@meduniwien.ac.at

Accepted 21 October 2012 Published Online First 21 November 2012

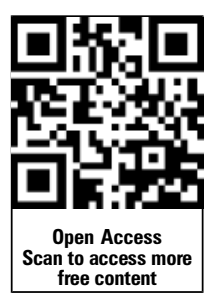

\section{ABSTRACT}

Background Since approval of tocilizumab (TCZ) for treatment of rheumatoid arthritis (RA) and juvenile idiopathic arthritis (JIA), interleukin 6 (IL-6) pathway inhibition was evaluated in trials of TCZ and other agents targeting the IL-6 receptor and ligand in various RA populations and other inflammatory diseases. This consensus document informs on interference with the IL-6 pathway based on evidence and expert opinion. Methods Preparation of this document involved international experts in RA treatment and RA patients. A systematic literature search was performed that focused on TCZ and other IL6-pathway inhibitors in RA and other diseases. Subsequently, incorporating available published evidence and expert opinion, the steering committee and a broader expert committee (both including RA patients) formulated the current consensus statement

Results The consensus statement covers use of TCZ as combination- or monotherapy in various RA populations and includes clinical, functional and structural aspects. The statement also addresses the second approved indication in Europe JIA and non-approved indications. Also early phase trials involving additional agents that target the IL-6 receptor or IL-6 were evaluated. Safety concerns, including haematological, hepatic and metabolic issues as well as infections, are addressed likewise.

Conclusions The consensus statement identifies points to consider when using TCZ, regarding indications, contraindications, screening, dose, comedication, response evaluation and safety. The document is aimed at supporting clinicians and informing patients, administrators and payers on opportunities and limitations of IL-6 pathway inhibition.

\section{SCOPE AND PURPOSE}

The treatment of rheumatoid arthritis (RA) has significantly advanced over the past decade with the recent optimisation of the use of synthetic disease modifying anti-rheumatic drugs (sDMARDs), such as methotrexate (MTX), ${ }_{1}{ }_{2}^{2}$ newly developed sDMARDs, such as leflunomide, ${ }^{3}{ }^{4}$ and with the addition of biological DMARDs (bDMARDs) to the RA therapeutic armamentarium. The first bDMARDs studied and subsequently approved were inhibitors of tumour necrosis factor (TNFi) ${ }^{5} 6$ followed by abatacept, an inhibitor of T-cell costimulation, ${ }^{7}$ rituximab, an agent leading to B-cell depletion $^{8}$ and tocilizumab (TCZ), an interleukin 6 (IL-6) receptor blocker. Although there is little direct comparison data between the five currently approved TNFi (adalimumab, certolizumab pegol, etanercept, golimumab and infliximab) or other bDMARDs, reviews and meta-analyses of clinical trial data suggest these compounds have similar efficacy ${ }^{9-12}$ They differ in terms of molecular structures (chimeric, humanised or human monoclonal antibodies, or recombinant receptor constructs), route of application (intravenous or subcutaneous), and adverse event profiles, with these differences determined by the agents' modes of action. In contrast to bDMARDs, the modes of action of sDMARDs are generally not well-understood, their adverse event profiles are mostly different and their costs are substantially lower.

Given the variety of available therapies and in light of the variability discussed above, recommendations for the management of RA have been developed. $^{13} 14$ However, these recommendations, despite their sophisticated and quite comprehensive nature, capture only parts of the complexity of the application of individual drugs. Therefore, consensus statements on the use of groups of agents or individual classes of agents have been developed, providing pertinent information for various stakeholders. ${ }^{15} 16$ Developing recommendations for individual classes of drugs may bear the value of 
providing more detailed information on a particular agent than can usually be offered by more general presentations. This is especially true for describing the safety aspects of certain therapeutics, but can also be true for deliberations with regard to efficacy.

In the present manuscript, inhibition of the effects of IL-6 was the focal point of a consensus activity. Interference with IL-6 is currently possible by using TCZ, a humanised monoclonal antibody directed against the IL-6 receptor (IL-6-R), but other compounds, such as another antibody targeting the IL-6R and several agents focusing on the cytokine IL-6 itself, are currently in development. ${ }^{17-20}$

An international group of experts and patient representatives experienced in clinical research, the use of biological agents and the development of consensus statements and treatment recommendations, convened in Vienna in March 2012 to develop a consensus statement on the current use of IL-6 pathway inhibition in rheumatology. This statement targets primarily those health professionals who prescribe IL- 6 inhibition related therapies, health professionals who do not primarily prescribe the agent but care for patients treated with TCZ, as well as patients interested in information on IL-6R or IL-6 inhibition. In addition, this document may also be informative to payers, hospital managers, administrators and other stakeholders interested in treating RA and other chronic inflammatory diseases.

The consensus statement will address the following areas:

- Background on IL-6 and mode of action of TCZ and other compounds

- Indication, considerations and screening for initiating TCZ in RA

- Treatment dose algorithm and co-medication

- Evaluation of response and management of response

- Predictive factors of response

- Contraindications and adverse events

- Long-term exposure-efficacy and safety issues

- Patient perspectives

- Research agenda

To achieve these objectives, a systematic literature review (SLR) of the published literature on the efficacy and safety of TCZ and steering other biologicals inhibiting the IL- 6 pathway in patients with RA was first undertaken to identify relevant data, which also included abstracts of recent international conferences, such as the European League Against Rheumatism (EULAR) and American College of Rheumatology (ACR) meetings of 2011 and abstracts known to be submitted to EULAR 2012 to be used and referenced if accepted for presentation. The results of this SLR ${ }^{21}$ were presented to and discussed by the committee, providing the basis for the discussions of the large task force and the conclusions that will be presented herein. Levels of evidence will be indicated next to each recommendation, in line with published guidelines (see also online supplement). ${ }^{22}$

\section{BACKGROUND}

IL-6 is a small polypeptide of approximately $26 \mathrm{kD}$ molecular weight that is involved in the differentiation and growth of a variety of cells. ${ }^{23}{ }^{24}$ It has originally been described as B-cell stimulating factor, hepatocyte stimulating factor and interferon $\beta 2$, before it was cloned ${ }^{23} 24$ and shown that all these activities were attributable to a single molecule which did not convey antiviral actions. IL- 6 binds to a receptor (IL-6R), which consists of the actual cytokine binding part, the IL-6R $\alpha$ chain, and a second moiety, gp130, which transduces the respective signals into the cell. A number of recent reviews have covered its mode of action and related aspects in detail, and the reader is referred to these and similar publications. ${ }^{23-27}$ More detailed insights are also summarised in the online supplementary files.

TCZ, a humanised anti-IL-6R antibody directed to the IL-6R $\alpha$ chain, is currently the only IL-6 pathway inhibitor licensed for the treatment of RA, and the evidence available on safety and efficacy therefore rests almost exclusively on information related to this agent. However, other IL- 6 inhibiting therapies are currently in development and phase 2 data already partly available; this information is also included in our analysis.

\section{MODE OF ACTION}

Inhibition of the effects of IL- 6 has been primarily studied in a number of phase II and III clinical trials of TCZ. The original designation of the antibody was myeloma receptor antibody, since IL- 6 is a growth factor for myeloma cells. TCZ showed initial clinical efficacy in collagen-induced arthritis in monkeys ${ }^{28}$ in a rare lymphoproliferative disorder, Castleman's disease; $^{29} 30$ and also in early phase evaluations in RA. ${ }^{29} 31-34$ Its effects on acute phase reactant (APR) levels and other features of chronic inflammation are fully in line with inhibition of the above-mentioned modes of action of IL-6. However, it is currently unknown if cells to which an anti-IL-6R antibody binds, are lysed, undergo apoptosis, are ingested by phagocytes of the spleen or others, or simply circulate with their receptor being blocked. It is also unknown if binding of such antibodies to the receptors might lead to cap formation and subsequent ingestion of the IL-6R. These questions need to be addressed as part of the research agenda.

\section{RECOMMENDATION FOR THE USE OF TCZ}

Indication, considerations and screening for initiating

TCZ in RA

Indication

Adult RA

In line with the current licensed indication in Europe, TCZ may be used in adult patients with active RA, normally with at least moderate disease activity according to a validated composite measure, who have had an inadequate response to, or intolerance of at least one synthetic DMARD and/or TNF-inhibitor. ${ }^{35}$

Before concluding that a patient has not sufficiently responded to a previous synthetic DMARD or a TNF-blocker, attempts should be made to improve the ongoing regimen by optimising the respective DMARD or TNF-blocker dose, if indicated, considering pertinent recommendations. ${ }^{14}$

TCZ fulfilled the requirements for the above indications as a consequence of the results of several clinical trials (level 1a, grade $\mathrm{A}$ ). In table $1 \mathrm{~A}$, the response rates according to the ACR improvement criteria $^{36}$ as observed in phase III clinical trials are depicted, showing superiority to control arms in all studies. A significant decrease in the disease activity score using 28 joint counts (DAS28) and high proportions of EULAR moderate and good response as well as DAS28 remission (DAS28<2.6) rates have been observed. However, interpretation of the LATTER data is impeded by the high weight of the APR component in the DAS28 formula ${ }^{37} 38$ and the prominent effect of IL-6 inhibition on the hepatic APR production, which can lead to exaggerated improvement or response rates when this measure is employed. Nevertheless, the pre-eminent requirement of improvement in both swollen and tender joints to fulfil ACR improvement criteria $^{36}$ and the published clinical trial data showing a decrease in disease activity across all variables studied as well as functional improvement and structural 
Table 1A ACR20, 50 and 70\% response rates (\% of patients fulfilling improvement criteria) and percentage of HAO change from baseline or fulfilment of HAQ-MCID (reduction of more than 0.22 ) in different clinical trials of TCZ

\begin{tabular}{|c|c|c|c|c|c|c|}
\hline FU & Study & $\begin{array}{l}\% \text { of patients } \\
\text { fulfilling } \\
\text { ACR20 }\end{array}$ & $\begin{array}{l}\% \text { of patients } \\
\text { fulfilling } \\
\text { ACR50 }\end{array}$ & $\begin{array}{l}\% \text { of patients } \\
\text { fulfilling } \\
\text { ACR70 }\end{array}$ & $\begin{array}{l}\text { HAQ-decrease from } \\
\text { baseline }(\%)\end{array}$ & Comment \\
\hline \multicolumn{7}{|c|}{ TCZ combination therapy } \\
\hline 16 weeks & $\begin{array}{l}\text { CHARISMA }^{33} 7 \text { arms, escalating doses of } \\
\text { TCZ monotherapy ( } 2 \text { vs } 4 \text { vs } 8 \mathrm{mg} / \mathrm{kg} \text { ) } \\
\text { versus each dose in combination with MTX } \\
\text { Results for } 8 \mathrm{mg} / \mathrm{kg} \text { combination therapy } \\
\text { versus MTX }\end{array}$ & $74 / 41$ & $53 / 29$ & $37 / 16$ & & MTX-IR \\
\hline 24 weeks & 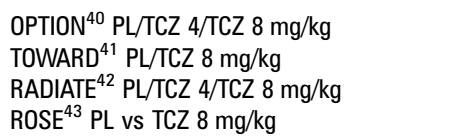 & $\begin{array}{l}26 / 48 / 59 \\
25 / 61 \\
10 / 30 / 50\end{array}$ & $\begin{array}{l}11 / 31 / 44 \\
9 / 38 \\
4 / 17 / 29 \\
11 / 30\end{array}$ & $\begin{array}{l}2 / 12 / 22 \\
3 / 21 \\
1 / 5 / 12\end{array}$ & $\begin{array}{l}21 / 33 / 34 \\
13 / 33^{*} \\
0 / 18 / 23\end{array}$ & $\begin{array}{l}\text { MTX-IR } \\
\text { MTX/DMARD-IR } † \\
\text { Anti-TNF-IR } \\
\text { DMARD-IR } †\end{array}$ \\
\hline 52 weeks & LITHE ${ }^{44} \ddagger$ PL/TCZ 4/TCZ 8 mg/kg & $25 / 47 / 56^{*}$ & $10 / 29 / 36^{*}$ & $4 / 16 / 20^{*}$ & $26 / 35 / 39^{*}$ & MTX-IR \\
\hline \multicolumn{7}{|c|}{ TCZ monotherapy } \\
\hline 12 weeks & Japanese ${ }^{34} \mathrm{PL} / \mathrm{TCZ} 4$ vs 8 mg/kg & $11 / 57 / 78$ & $2 / 26 / 40$ & $0 / 20 / 16$ & & DMARD-IR \\
\hline 16 weeks & $\begin{array}{l}\text { CHARISMA } 7 \text { arms, escalating doses of } \\
\text { TCZ monotherapy ( } 2 \text { vs } 4 \text { vs } 8 \mathrm{mg} / \mathrm{kg} \text { ) } \\
\text { versus each dose in combination with MTX } \\
\text { Results for } 8 \mathrm{mg} / \mathrm{kg} \text { monotherapy vs MTX }\end{array}$ & $63 / 41$ & $41 / 29$ & $16 / 16$ & & MTX-IR \\
\hline \multirow[t]{4}{*}{24 weeks } & AMBITION ${ }^{45}$ MTX/TCZ 8 mg/kg & $53 / 70$ & $34 / 44$ & $15 / 28$ & $33 / 44$ & \\
\hline & $\begin{array}{l}\text { ACT-RAY } 4647 \mathrm{TCZ} 8 \mathrm{mg} / \mathrm{kg} / \mathrm{TCZ} 8 \mathrm{mg} / \mathrm{kg} \\
+\mathrm{MTX}\end{array}$ & $70 / 72$ & $40 / 46$ & $25 / 25$ & $33 / 33^{*}, \S$ & $\begin{array}{l}\text { MTX-IR, switch to vs adding TCZ; LDA } \\
\text { and DAS28-REM were more frequent on } \\
\text { combination than TCZ mono-therapy }\end{array}$ \\
\hline & SATORI ${ }^{48} \mathrm{MTX} / \mathrm{TCZ} 8 \mathrm{mg} / \mathrm{kg}$ & $25 / 80$ & $11 / 49$ & $6 / 30$ & $25 / 50^{*}$ & MTX-IR \\
\hline & $\begin{array}{l}\text { ADACTA }^{49}{ }^{4 C Z} 8 \mathrm{mg} / \mathrm{kg} / \text { adalimumab } \\
40 \mathrm{mg}\end{array}$ & $65 / 49$ & $47 / 28$ & $33 / 18$ & n.a. & Adalimumab monotherapy \\
\hline 52 weeks & SAMURAI $^{50}$ DMARDs/TCZ 8 mg/kg & $34 / 78$ & $13 / 64$ & $6 / 44$ & $10 / 50^{*}$ & DMARD-IR \\
\hline \multicolumn{7}{|c|}{ Other IL-6 or IL-6R inhibitors (phase II; week 12) } \\
\hline \multirow[t]{4}{*}{12 weeks } & $\begin{array}{l}\text { Anti-IL-6R } \\
\text { Sarilumab } 51 \mathrm{PL} / 150 \mathrm{mg} \\
\text { Anti-IL-6 }\end{array}$ & $46 / 72$ & n.a. & n.a. & n.a. & \\
\hline & BMS945429 ${ }^{19}$ PL/active & $36 / 82 \uparrow$ & $15 / 50$ & $6 / 43$ & $29 / 39$ & \\
\hline & Sirukumab ${ }^{17} \mathrm{PL} /$ active & $30 / 639$ & $3 / 27$ & n.a. & n.a. & \\
\hline & Olokizumab $^{18}$ & n.a. & n.a. & n.a. & n.a. & \\
\hline
\end{tabular}

* Estimated values using baseline data and approximate values from respective curves, since exact data not provided in the publications.

tDMARDs aside from MTX: sulfasalazine, leflunomide, antimalarials and other.

$\ddagger 1$ year data.

§Differences between groups in ACT-RAY not significant; all other studies showed significant differences from control; where studied, 4 mg/kg dose was also significantly

different from control; details see individual publications.

THighest response rate among several arms.

ACR, American College of Rheumatology; DMARDs, disease modifying antirheumatic drugs; DAS-28, disease activity score using 28 joint counts; FU, weeks of follow-up; HA0, Health Assessment questionnaire disability index; IR, insufficient response; LDA, low disease activity; MCID, minimally clinically important difference; MTX, methotrexate; n.a., not available; PL, placebo; TCZ, tocilizumab; TNF, tumour necrosis factor; for trial acronyms see respective publications.

effects (table 1B), provide evidence that TCZ is an effective biological disease modifying drug. Indeed, when focusing on the clinical disease activity index (CDAI), a score that does not comprise an APR in its formula, TCZ remains significantly effective. $^{39}$ Its efficacy appears to be of similar magnitude as that of TNF-inhibitors, abatacept and rituximab. ${ }^{9}$

TCZ has shown superior efficacy compared with control groups in the treatment of RA manifestations in combination with MTX and other sDMARDs; TCZ was assessed mostly in combination with MTX, but in some studies up to $20 \%$ of the patients received other sDMARDs like leflunomide, sulfasalazine and/or chloroquine/hydroxychloroquine without noticeable differences in efficacy. ${ }^{41} 52$ TCZ was also effective as monotherapy. Studies of other biologicals employed as monotherapy mostly revealed similar efficacy as MTX and had generally less efficacy than combination therapy. ${ }^{10} 1214$ By contrast, TCZ monotherapy has been shown in Japanese and an international trial to convey significantly better efficacy compared with MTX (in MTX naïve or MTX never failed patients) or other DMARDs in clinical, functional and, in the SAMURAI trial, also structural respects, although it should be borne in mind that in the Japanese studies MTX was dosed at only $8 \mathrm{mg}$ weekly (level 1b, grade A; table 1A). ${ }^{45} 4850$ A recent trial comparing TCZ monotherapy with adalimumab monotherapy (ADACTA trial) revealed clinical superiority of TCZ. ${ }^{49}$ While this finding is not surprising given the fact that adalimumab monotherapy was not shown to be clinically superior to MTX monotherapy in early $\mathrm{RA}^{53}$ (and TCZ monotherapy was not compared with a combination of $\mathrm{ADA}+\mathrm{MTX}$ ), the data implicitly confirm the previous findings on the efficacy of TCZ monotherapy compared with DMARDs studied hitherto. ${ }^{45} 4850$ For monotherapy, the $8 \mathrm{mg} / \mathrm{kg}$ dose is the only one studied in phase 3 trials.

Adding TCZ to MTX (combination therapy) compared with switching from MTX to TCZ monotherapy (withdrawal of MTX) failed to convey superior clinical and structural effects in 
Table 1B Radiographic changes in TCZ clinical trials assessing joint damage

\begin{tabular}{lllllll}
\hline Study & Placebo+MTX & $\mathbf{4} \mathbf{~ m g} / \mathbf{k g}+\mathbf{M T X}$ & $\mathbf{8} \mathbf{~ m g} / \mathbf{k g}+\mathbf{M T X}$ & $\mathbf{8} \mathbf{~ m g} / \mathbf{k g}$ mono-therapy & DMARDs & Assessment \\
\hline${\text { LITHE }{ }^{44}}^{4}$ & 1.13 & $0.34^{*}$ & $0.29^{*}$ & & & GTSS, mean change from baseline \\
SAMURAIt & & & & $2.3(1.5-3.2)^{* *}$ & $6.1(4.2-8.0)$ & vdH-TSS, mean (95\%CI) change from baseline \\
ACT-RAY ${ }^{46}$ & & & $0.08(1.88)$ & $0.22^{* * *}(1.11)$ & Change of GTSS at 6 months; mean (SD) \\
ACT-RAY ${ }^{47}$ & & & $92.4 \%$ & $85.5 \% * * * *$ & No radiographic progression at 1 year \\
\hline
\end{tabular}

${ }^{*} \mathrm{p}<0.0001 ;{ }^{* *} \mathrm{p}<0.001 ;{ }^{* *} \mathrm{p}=0.26 ;{ }^{* * *} \mathrm{p}=0.007$; using as a cutoff the smallest detectable change of the Genant modified Sharp score of 1.5 (a relatively high value as a cutoff for non-progression; data on lower values, such as 0 or 0.25 are awaited).

†The LITHE and SAMURAI data, including $\mathrm{p}$ values, relate to 1 year study results; for ACT-RAY, data shown reflect 6-month analyses which showed no significant differences between TCZ monotherapy and combination with MTX.

DMARDs, disease modifying antirheumatic drugs; GTSS, Genant-modified total Sharp score; MTX, methotrexate; TCZ, tocilizumab; vdH-TSS, van der Heijde modified total Sharp score.

patients with established RA and active disease despite MTX treatment for most endpoints (ACT-RAY trial; table 1A). ${ }^{46}$ Thus, these data further imply that monotherapy is effective and is not significantly inferior to combination therapy. However, many of the assessments showed better numerical outcomes in the combination therapy; moreover, at 6 months and 12 months, significantly more patients achieved DAS28 low disease activity or remission, respectively, and less patients had progression of joint damage on combination therapy compared with monotherapy. ${ }^{47}$ Thus, while TCZ monotherapy is superior to MTX monotherapy, a number of patients may benefit from the combination more than from switching to monotherapy. However, if combination with MTX or other DMARDs is contraindicated and monotherapy with a biological agent is mandated, TCZ should be considered. In light of all of the above aspects, a 3-arm trial comparing MTX, TCZ and the combination in early RA is still awaited to clarify these questions.

Throughout all studies assessing a $4 \mathrm{mg} / \mathrm{kg}$ and an $8 \mathrm{mg} / \mathrm{kg}$ dose in combination with MTX, both doses had significantly better efficacy than control regarding clinical functional and structural outcomes, ${ }^{444042}$ but there was a consistent (though statistically not significant) clinical superiority of the higher dose (table 1A), which was particularly prominent for more profound levels of efficacy (eg, ACR70) and in patients who have failed TNFi; these data suggest that many patients receiving TCZ at $4 \mathrm{mg} / \mathrm{kg}$ will have only a limited, inadequate response and a majority no profound response (level 1c, grade A). Trials investigating an increase to $8 \mathrm{mg} / \mathrm{kg}$ after a starting dose of $4 \mathrm{mg} / \mathrm{kg}$, as currently recommended in the US, have not been systematically performed, although in the clinical trials evaluating the $4 \mathrm{mg} / \mathrm{kg}$ dose, rescue therapy with $8 \mathrm{mg} / \mathrm{kg}$ had been implemented in patients who did not achieve at least 20\% improvement in tender and swollen joint counts by week 16; ;4 $^{40}$ moreover, in a post-hoc analysis TNFi-insufficient responders (IR) and MTX-IR patients not achieving an adequate response to TCZ $4 \mathrm{mg} / \mathrm{kg}$ by week 16 showed improvement after escalation to $8 \mathrm{mg} / \mathrm{kg}$. ${ }^{54}$ Importantly, the rate of anaphylactic reactions appears to be several fold higher at the $4 \mathrm{mg} / \mathrm{kg}$ than at the $8 \mathrm{mg}$ dose of TCZ (see below). ${ }^{55}$ A lower dose than $4 \mathrm{mg} / \mathrm{kg}$ is not recommended because of its insufficient efficacy and even higher risk of immunogenicity. ${ }^{33}$ In general, based on the available data, the task force felt that starting combination therapy with a dose of $8 \mathrm{mg} / \mathrm{kg}$ and possibly decreasing the dose when necessitated by adverse events may be more appropriate than starting at $4 \mathrm{mg} / \mathrm{kg}$ due to the better efficacy and lesser immunogenicity of the higher dose; clinical and laboratory monitoring is necessary at either dose.

TCZ has also shown significant effects on retarding progression of joint damage, both in combination as well as monotherapy; ${ }^{50} 4644$ structural efficacy was observed at both $4 \mathrm{mg} / \mathrm{kg}$ and $8 \mathrm{mg} / \mathrm{kg}$, where studied (table 1B). Moreover, TCZ inhibited x-ray progression in patients with low as well as persistent high clinical disease activity, thus dissociating the tight link between disease activity and joint damage, as also seen with TNF-blockers. ${ }^{56}$ TCZ is effective across all populations investigated, that is, established and early RA; MTX-naïve, ${ }^{45}$ DMARD-IR ${ }^{33} 415248464440$ and TNFi-IR ${ }^{42}$ patients (level $1 \mathrm{a}$ to $1 b$, grade $A)$. No differences in efficacy were seen between patients positive or negative for rheumatoid factor. ${ }^{52} 57$

In line with its mode of action, TCZ leads to a rapid reduction in APR, including C-reactive protein (CRP) levels, which is sustained at the $8 \mathrm{mg} / \mathrm{kg}$ dose; in contrast, with $4 \mathrm{mg} / \mathrm{kg}$ CRP decreases are not maintained throughout the 4 week time course and this saw tooth pattern suggests an inadequate suppression of the pathway at this dose. ${ }^{41} 444042$ Further, TCZ leads to an increase in haemoglobin levels, especially in RA patients with anaemia, presumably by inhibiting the production of hepcidin, a molecule stimulated by IL- 6 and involved in the pathways to anaemia of chronic disease; ${ }^{58}$ it may be thus useful in RA patients with otherwise refractory anaemia of chronic disease. The adverse event profile will be discussed in detail in subsequent sections.

\section{Considerations for initiating treatment}

Before starting any treatment for RA in general and thus also TCZ, an individual therapeutic goal should be determined as a shared decision between the patient and the treating physician, who should be experienced in the diagnosis and treatment of RA as well as the use of biological therapies and their complications $^{14} 59$ (level 5, grade D). Several studies have shown that RA patients cared for by physicians experienced in the management of their disease, thus primarily rheumatologists, have better outcomes than those followed by less specialised physicians. ${ }^{60} 61$ Patients to whom the rheumatologist suggests treatment with TCZ should have at least moderate disease activity by composite scores, such as the DAS28 (>3.2), the Simplified or CDAI (SDAI>11; CDAI $>10)$ or similar scores $^{62}$ (level 5, grade $\mathrm{D})$. A raised CRP is also preferable.

In the phase III trials, TCZ was started in patients with an inadequate response to sDMARDs ${ }^{4144} 40$ or also TNFi. ${ }^{42}$ TCZ was used in combination with sDMARDs, primarily MTX, or as monotherapy. ${ }^{33} 45 \quad 50 \quad 46 \quad 44$ When TNFi preceded TCZ therapy, requirements for time of discontinuation were different among prior agents: for etanercept it was at least 2 weeks, while for adalimumab and infliximab at least 8 weeks. ${ }^{42}$ In an open label phase IV study, TCZ therapy was used within 1 month of stopping TNFi without any increases in serious infections or other safety signals. ${ }^{63}$ In clinical practice it is likely that TCZ will be frequently applied earlier than after such intervals; however there are no available data supporting the safety of TCZ in such cases. ${ }^{64}$ Of note, TCZ has not yet 
been studied in patients who had been previously exposed to rituximab or abatacept, although data from an observational study of small cohorts suggest some risk of infections in its use after rituximab. Thus, more information will have to be obtained from further trials or soon become available from registries. Data from registries of patients receiving TCZ are currently limited, ${ }^{65}$ but the registries will provide additional information on the use of co-medications or patients treated in the presence of comorbidities that were excluded from clinical trials, as patients in clinical practice are usually more heterogeneous in these respects compared with trial populations.

\section{Screening before initiating TCZ}

In general, patients should be well informed about the risks and benefits of TCZ therapy (level 5 , grade $\mathrm{D}$ ).

Initiation of TCZ should be preceded by obtaining a detailed history regarding chronic or recent co-morbidity, such as cardiovascular, liver and pulmonary diseases, recurrent infections, allergies, gastrointestinal perforations or diverticulitis, pregnancy or plans to become pregnant, and a complete physical examination to consider possible contraindications in all patients, especially the elderly. Special attention should be paid to vaccinations which should be performed in accordance with respective recommendations ideally before the administration of TCZ. ${ }^{66}$ During TCZ therapy vaccination with live vaccines (which includes rubella and shingles vaccines) should be avoided (level 5, grade D).

A history of diverticulitis (note, not diverticulosis) should alert the patient and treating physician, to a heightened risk of gastrointestinal perforations during TCZ therapy. Gastrointestinel (GI) perforations have been reported (incidence $0.1-0.2 \%$ ), especially in patients with such history ${ }^{35} 5567$ (level 4 , grade $\mathrm{C}$ ), although most were on glucocorticoids or nonsteroidal antirheumatic drugs (NSAIDs). Indeed, recent data indicate that RA patients, regardless of DMARD therapy, have a generally increased rate of GI perforation including both the upper and lower GI tract, and the risk factors for this complication are glucocorticoid therapy, NSAIDs, and diverticulitis history among others. ${ }^{68}$ At this time, further information is needed to understand whether TCZ or other IL-6 inhibitors further increase the risk of this complication beyond that observed in the general RA population. Until then, however, when IL-6 blocking therapy is prescribed in such patients, efforts to eliminate or mitigate known risk factors for perforation should be undertaken where possible, and vigilance for this potential complication should be maintained.

In clinical trials of TCZ, patients with RA were screened for hepatitis $B$ and $C$ and excluded if testing positive. Likewise, patients were excluded if they had active liver disease, indicated by screening and baseline concentrations of alanine or aspartate aminotransferase of 1.5 times the upper limit of normal (ULN) or more. Of note, hepatic transaminase increases occurred more frequently when TCZ was used in combination with MTX as compared to monotherapy. The safety of TCZ in patients with active hepatitis $\mathrm{B}$ or $\mathrm{C}$ virus ( $\mathrm{HBV}, \mathrm{HCV}$ ) infections is currently unknown. Clearly, in the presence of acute viral hepatitis TCZ therapy is contraindicated. Also, in patients with chronic hepatitis B with poor liver function, TCZ therapy is not recommended. In Japan, several case reports have been published in which two HBV patients, in the context of concomitant antiviral therapy, and one HCV patient were successfully treated with TCZ, ${ }^{6-72}$ and in a postmarketing surveillance report no hepatobiliary disorders due to reactivation of hepatitis $\mathrm{B}$ or $\mathrm{C}$ have been seen ${ }^{73}$ (level 4, grade C). Thus, in patients with chronic hepatitis B and moderate to good liver function, treatment with antiviral agents should be performed before considering TCZ therapy. In HBV carriers or in patients with latent $\mathrm{HBV}$ infection (ie, $\mathrm{HBs}$ antigen negative, $\mathrm{HBc}$ or $\mathrm{HBs}$ antibody positive) who show positive HBV DNA in peripheral blood, prophylaxis should be considered before starting TCZ. Thus, until further safety data are collected, TCZ treatment in patients with chronic viral hepatitis can currently not be recommended without antiviral prophylaxis in case of hepatitis $\mathrm{B},{ }^{71}$ especially since reactivation of viral hepatitis has been reported for other biological agents, such as TNF-inhibitors, abatacept and rituximab ${ }^{74-77}$ (level 5 , grade D).

While preclinical studies have not clearly defined the role of IL-6 in the defence against Mycobacterium tuberculosis, ${ }^{78}$ the occurrence of tuberculosis has been reported in clinical trials and postmarketing surveillance studies of $\mathrm{TCZ}^{73}{ }^{79}$ (level 4, grade C) and, therefore, patients should be screened for latent tuberculosis according to local recommendations in the same manner as for other biologicals; in the pivotal clinical trials patients had been screened for tuberculosis. Chemoprophylaxis prior to TCZ initiation should be given in patients diagnosed with latent tuberculosis infection (level 5, grade D). Patients with active tuberculosis are contraindicated for treatment with TCZ.

Glucocorticoid therapy should be recorded and minimised or tapered as rapidly as possible, since there are indications that the risk of serious infections including opportunistic infections is higher in TCZ treated patients with concomitant glucocorticoid therapy than in those without ${ }^{73}$ (level 4 , grade C).

Regarding safety during and after pregnancy, currently only limited data exist; ${ }^{80}{ }^{81}$ there is no apparent evidence that IL-6 plays a role in fertility or gestation or TCZ leads to malformations, though IgG antibody transmission across the placenta has been demonstrated with other biological agents. Nevertheless, women of childbearing potential should use effective contraception during and until 3 months after cessation of therapy. Currently it cannot be suggested to continue TCZ therapy in women who become pregnant because only insufficient safety data exist; on the other hand, therapeutic abortion relies on a thorough discussion between the physician and the mother. Also, breast-feeding should not be done during TCZ therapy (level 5, grade D)

\section{Administration of TCZ in combination therapy and monotherapy}

TCZ is administered as a monthly intravenous infusion, usually over 1 hour. The approved initial dose in Europe and most other regions of the world is $8 \mathrm{mg} / \mathrm{kg}$, while in the USA it is $4 \mathrm{mg} / \mathrm{kg}$. The maximum recommended dose is $800 \mathrm{mg}$ for people with $\geq 100 \mathrm{~kg}$ bodyweight. ${ }^{3555}$ A subcutaneous formula is currently under investigation. Other IL-6 blockers that are currently in phase 2 or 3 studies (see table 1A) are also applied by the subcutaneous route.

TCZ is approved for use in combination with MTX and as monotherapy if MTX is not tolerated or inappropriate. However, TCZ has also been used in combination with a variety of other sDMARDs. ${ }^{52} 82$

While it is recommended to lower the dose of TCZ when certain adverse effects occur (see below), it is not clear at present how one should proceed once patients reach the treatment target, such as clinical remission or sustained low disease activity: can the dose be reduced, the interval between infusions expanded, or should full treatment be continued? In a Japanese study, only $13 \%$ of the patients maintained low disease activity over 1 year after cessation of TCZ without use of any 
DMARDs. If the patients normalised MMP-3 and had low IL-6 levels, the retention rate reached $38 \%{ }^{83}$ Further study will need to assess the impact of disease duration and DMARDs use on the duration of response after TCZ is discontinued. It is also unknown whether there will be a difference in the duration of sustained efficacy between early and established RA.

\section{Evaluation of response and management of non-response}

Response assessment should be done using composite measures of disease activity, such as DAS, DAS28, SDAI and CDAI. However, it should be borne in mind that APR are included in all of these except for the CDAI. Because the effect of IL-6 inhibition on CRP levels or ESR may be profound despite lack of clinical improvement, the actual response may be obscured (see above). Therefore measures that do not comprise an APR, such as the CDAI, are preferred (level 5, grade D). For the future, treatment goals based on modern imaging modalities that assess inflammatory activity, such as sonography or MRI, if shown to be associated with important outcomes, may be particularly relevant for patients using TCZ

In line with respective recommendations, ${ }^{13} \quad 14 \quad 59$ disease activity assessment should be done initially monthly to every 3 months, aiming at a significant improvement within 3 months and attaining low disease activity (CDAI $\leq 10$, $\mathrm{SDAI} \leq 11$, DAS28<3.2) or remission (using ACR-EULAR remission criteria ${ }^{84}$ ) within 6 months (level 5 , grade D). Clinical trial data suggest that clinical efficacy is already seen within a few weeks ${ }^{41} 4540$ and, therefore, support the validity of the above recommendations for response expectations.

If a patient does not achieve low disease activity within 6 months at an adequate dose (or does not experience a significant improvement of disease activity within 3 months) another treatment option should be considered (level 5 , grade D).

However, in the USA, where a starting dose of $4 \mathrm{mg} / \mathrm{kg}$ is licensed (and which may convey more immunogenicity and lower response rates as discussed above), a dose escalation may have to be considered much earlier if significant improvement is not attained. Specific data to guide such dose escalation are not well elaborated yet, since in clinical trials a dose increase from 4 to $8 \mathrm{mg}$ was usually done only after 16 weeks and only in patients failing to achieve $20 \%$ reduction in tender and swollen joint counts, a quite minimalistic requirement given the baseline disease activity and length of time. Thus, in the case of dose escalation, judging response adequacy may be more appropriate after 3 and 6 months at the generally accepted therapeutic dose of $8 \mathrm{mg} / \mathrm{kg}$.

\section{Cost-effectiveness}

Despite the relatively limited time since approval, some economic analyses on the use of TCZ have been published and, with all reservations regarding such analyses at a relatively early stage of use, revealed cost-effectiveness. ${ }^{85} 86$ More data will be needed for full appreciation of the health economic aspects of TCZ use.

\section{Contraindications, adverse effects and long-term exposure}

TCZ has been studied in several international and Japanese trials, and most of these trials had long-term extension phases. The long-term safety in Japanese patients as well as in the international studies has been reported, ${ }^{87} 88$ and also the SLR informing the present recommendations has focused partly on safety; ${ }^{21}$ the reader is referred to these publications as well as the package insert. ${ }^{35} 55$ 87-89 A brief summary of adverse events as derived from the above-mentioned studies and the package insert is also provided in the online supplementary files, and some have been discussed above under "Screening before initiating TCZ". The items primarily addressed in the online supplement are hypersensitivity, infections including hepatitis, malignancies, changes of blood counts, lipids, gastrointestinal perforations, hepatic manifestations and cardiovascular risk.

\section{Dose adaptation or discontinuation in case of adverse events}

\section{and monitoring recommendations}

While it is evident that in patients with infections, especially serious ones, TCZ therapy has to be interrupted or sometimes discontinued and therapy has to be withdrawn in the event of infusion reactions, there are also specific laboratory abnormalities that may require dose reductions or discontinuation. Thus if transaminase elevations in the range of $1-3 \times$ ULN persist, the dose should be reduced to $4 \mathrm{mg} / \mathrm{kg}$ or interrupted until normalisation; if transaminases increase to $>3 \times$ ULN, therapy should be interrupted and can be resumed at lower dose when levels are $<3 \times \mathrm{ULN}$, and resumed at $8 \mathrm{mg} / \mathrm{kg}$ after transaminase normalisation. For persistent (ie, seen at least twice) increases $>3 \times$ ULN or for any elevation $>5 \times$ ULN, TCZ should be permanently discontinued (level 5 , grade $\mathrm{D}$ ).

With respect to leukocytopenia, TCZ should be discontinued if neutrophil counts are $<500 / \mathrm{mm}^{3}$; at counts of $500-1000 /$ $\mathrm{mm}^{3}$, TCZ should be interrupted and resumed at $4 \mathrm{mg} / \mathrm{kg}$ once neutrophil counts increase to $>1000 / \mathrm{mm}^{3}$ (level 5 , grade D).

Liver enzymes and bilirubin, complete blood count with differential and lipid levels should be assessed every 4 to 8 weeks for the first 6 months and every 3 months thereafter (level 5, grade D).

\section{Patient perspectives}

TCZ not only improves clinical signs and symptoms and joint damage, but also all pertinent patient reported outcomes, such as pain, physical function and quality of life; moreover, fatigue, an important symptom identified by patients with RA, is significantly improved with TCZ. ${ }^{90}$ Patients should be fully informed by their rheumatologist about the benefits and risks of TCZ therapy. Treatment initiation as well as the treatment target should be based on a shared decision between the patient and physician and appropriately recorded (level 5 , grade D).

\section{Other indications and experiences}

While the focus of the present statement is on adult RA, several other indications should be mentioned. TCZ is also licensed in Europe and Japan for systemic juvenile idiopathic arthritis (sJIA). ${ }^{55}$ In Japan, TCZ is also approved for use in polyarticular JIA and Castleman's disease. These data are supported by respective publications ${ }^{30} 9192$ (level $1 \mathrm{~b}$ to $2 \mathrm{~b}$, grade $\mathrm{B}$ ). The specific indications and licensing may differ among other countries.

There are also a number of other diseases in which TCZ has been employed with or without success. According to several case reports, TCZ has been effective in patients with secondary amyloidosis, polymyalgia rheumatica, adult onset Still's disease, polymyositis, systemic sclerosis, large vessel vasculitis (such as giant cell arteritis), and it has also been used in Lupus with indications of some mild improvement. ${ }^{92-101}$ However, none of these conditions are licensed indications and more information will have to be obtained from formal clinical trials. In part, these findings are in line with data on IL- 6 inhibition in experimental models of these diseases. ${ }^{102}$ In patients with Castleman's disease who frequently experience an interstitial pneumonitis, lung disease has improved upon TCZ therapy. ${ }^{103} 104$ In contrast, TCZ has revealed negative results in case series and clinical trial of axial spondyloarthritis/ 
ankylosing spondylitis, ${ }^{105-107}$ and this was also the case for a study on sarilumab, another IL-6R inhibitor. ${ }^{108}$ Likewise, case reports in psoriatic arthritis showed no clinical effect of TCZ despite reduction in CRP, ${ }^{109}$ although these were small studies in refractory patients. Nevertheless, the potential efficacy of antibodies to IL-6 rather than the IL-6R is currently unknown, and the potential efficacy of IL-6R blockade in patients with peripheral spondyloarthritis remains to be investigated.

Finally, TCZ has also been evaluated in a small pilot controlled study of Crohn's disease and showed limited efficacy (20\% clinical remission without effects on endoscopic and histological changes) at doses of $8 \mathrm{mg} / \mathrm{kg}$ every other week. ${ }^{110}$

\section{Research Agenda}

The committee felt that many questions remained open and needed to be addressed in future research in both adult and paediatric populations. Some of these questions are presented herein; they focus on TCZ but would equally be pertinent for other compounds targeting the IL-6R or IL- 6 and might be addressed in the course of planned clinical trials.

Dose of TCZ and concomitant therapies

- Can TCZ be withdrawn, its dose reduced or the interval of its administration expanded successfully in patients who have attained low disease activity or remission?

- In the USA: when is it ideal to increase the TCZ dose from 4 to $8 \mathrm{mg} / \mathrm{kg}$ and what are the indicators that should lead to this dose increase?

- Is TCZ monotherapy similarly effective as combination therapy with MTX in early and established RA?

- What is the effect of other IL-6i when used as monotherapy?

Efficacy and assessment aspects

- What is the most suitable remission or low disease activity target for TCZ, taking into account the specific effect on APR (CDAI and/or a newer imaging modality with assessment of synovitis activity?)

- Is IL-6 pathway inhibition efficacious in patients with active disease but normal CRP levels?

- What are predictors of response to IL-6-blockers?

- What are the effects of IL-6 inhibition on systemic osteoporosis?

- Is the use of IL-6 inhibitors economically sound?

- What is the comparative efficacy and safety profile of TCZ compared to other biological agents?

Safety in relation to other targeted therapies

- What are the efficacy and safety when IL-6 pathway inhibitors are given to patients previously treated with rituximab (with or without persistent B-cell depletion) or abatacept?

- How safe are TNFi, abatacept and rituximab after IL-6i therapy and vice versa?

- How safe are IL-6 inhibitors when combined with other sDMARDs besides MTX?

- Are IL-6 inhibitors safe when used with or immediately after Jak inhibitors, once these are licensed?

- Is there a need for a washout period after other biologicals have been employed or can IL-6 inhibition be applied when the next dose of the other biological is scheduled? And vice versa, is there a need for a washout period for TCZ before another biological can be used?

General safety aspects

- Is there a risk in patients with solid malignancies in the previous 5 years upon IL6 inhibition?
- Can patients with past/recent lymphoma or myeloma be safely treated with TCZ?

- How safe are IL-6 inhibitors in patients with diabetes?

- What is the net effect of IL-6-blockers on cardiovascular risk?

- What is the mechanism for the change in lipids seen with IL-6-blocking treatment?

- What is the involvement of IL-6 in defence against Mycobacterium tuberculosis? Is the risk of reactivation of latent tuberculosis truly increased among patients who receive TCZ or other IL-6 inhibitors?

- Is the response to vaccines impaired during IL-6-blocker therapy as it is during rituximab treatment?

- Is the risk of herpes zoster (shingles) increased with IL-6 inhibition?

- What are the predictors of anaphylactic reactions?

- How safe is the use of IL-6i in patients with hepatitis B or C, treated with or without antiviral agents?

- Does the use of isoniazid lead to significant increases in liver function tests in patients with IL-6 inhibitor mono- and combination therapy?

- What is the risk of GI perforations in patients treated with IL-6-blockers? Is there any specific GI perforation associated with these compounds, in the upper or lower gastrointestinal tract? Is it related or unrelated to concomitant use of other drugs?

- Is there a risk to exacerbate or trigger demyelinating disorders during treatment with IL-6 inhibitors?

- Are some forms of autoimmunity triggered upon the use of IL-6 inhibiting therapy?

- Is there a need to stop therapy with IL-6-blockers before fathering a child?

- What is the molecular effect of TCZ on target cells?

Other indications and aspects

- Larger trials should be performed for diseases like vasculitis (including giant cell vasculitis), polymyalgia rheumatica, polyand dermatomyositis, systemic sclerosis, systemic lupus erythematosus, adult onset Still's disease, amyloidosis, and others.

- How should treatment with TCZ be approached in obese people?

- What is the efficacy and safety of using IL-6 inhibitors to treat extra-articular manifestations of RA, including interstitial lung disease and vasculitis?

\section{CONCLUSION}

In this consensus statement we provide recommendations for the use of IL-6 pathway inhibition in clinical practice. The data are primarily based on evidence assembled from clinical trials on TCZ, currently the only approved agent targeting this pathway, but also data of early phase clinical trials on other compounds that target both the IL-6 receptor and ligand have been considered. As far as available, these data confirm the efficacy and safety profile of IL-6 pathway blockade. Currently approved indications are adult rheumatoid and juvenile inflammatory arthritis. While other indications may follow with more available data, axial spondyloarthritis appears to be refractory to this therapy. The recommendations have been developed to provide guidance for rheumatologists and other physicians engaged in the treatment of inflammatory diseases as well as information for patients, payors and other stakeolders. They are summarised in the 'Points to Consider' (box 1). which provide only a synopsis of the discussions for purposes of general information. The details presented in the previous sections should be regarded as part and parcel of these points.

Additional data will be needed to fully understand the value of this treatment approach. Pertinent research question addressing 


\section{Box 1 Points to consider for the treatment of adult rheumatoid arthritis (RA) with tocilizumab (TCZ)*}

\section{Indication (level 1a, Grade A)}

- RA with inadequate response to (or intolerance of) at least one synthetic disease modifying antirheumatic drug (sDMARDs) or tumour necrosis factor (TNF) inhibitor

- Active RA (at least moderate disease activity according to a validated composite measure)

Contraindications (level 5, grade D)

- Allergy to TCZ

- Clinically relevant co-morbidities, particularly active infections

Pre-treatment screening (level 5, grade D)

- History and physical examination

- Consider possible contraindications

- Consider radiograph of the chest

- Assess history of infections, diverticulitis and malignancies

- Routine laboratory testing, including lipid levels

- Testing for hepatitis B and hepatitis C viral infections

- Screening for tuberculosis

- Assess necessity of vaccination

Treatment dose and co-medication (level 1a, grade A)

- $8 \mathrm{mg} / \mathrm{kg}$ every 4 weeks as intravenous infusion, usually over $1 \mathrm{~h}$

- While the approved starting dose in the US is $4 \mathrm{mg} / \mathrm{kg}$, this is not recommended by the task force.

- A reduction from 8 to $4 \mathrm{mg} / \mathrm{kg}$ may be needed upon occurrence of certain adverse events.

- TCZ can be used in combination with methotrexate (MTX) (alternatively in combination with other sDMARDs) or as monotherapy, if MTX is inappropriate.

- Evaluation and definition of response (level 5, grade D)

- Apply validated composite indices to assess treatment response

- Assess disease activity frequently especially during the first months after initiation of TCZ

- Aim for remission (American College of Rheumatology-European League Against Rheumatism remission definition) or low disease activity state (LDA: disease activity score using 28 joint counts $\leq 3.2$, simplified disease activity index $\leq 11$, Clinical disease activity index $\leq 10)$

- A significant improvement should be achieved after 12 weeks and the treatment target should usually be reached after 24 weeks; insufficient response should normally lead to switching to an alternative therapy.

- Aim for improvement in function and quality of life

- Progression of structural changes should be prevented

\section{Adverse events}

- Infusion reactions $(\sim 7 \%)$

- Severe infusion (hypersensitivity) reactions may occur but are rare (0.3\%); they are more frequent with the $4 \mathrm{mg} / \mathrm{kg}$ than the $8 \mathrm{mg} / \mathrm{kg}$ dose

- Serious infections occurred about twice as frequently with TCZ compared to placebo population

- Hepatic transaminase elevations

- Gastrointestinal perforations, primarily in patients with a history of diverticulitis

- Neutropenia and rarely thrombocytopenia

- Effects of uncertain relevance

- Lipid increases (should be treated according to local guidelines)

*These points are a short abbreviation of the items discussed and presented in detail in the body of the text or in the online supplement. They should not be applied independently of the information provided there in more detail, but present only an overview of the general scope of the recommendations.

open issues on safety, efficacy and optimised use have been formulated. The expected advancements will allow for a more refined use of TCZ and other IL-6 inhibitors in the future. However, the already available information and the development of many additional biologicals targeting IL-6 or its receptor reveal the importance of this treatment option to improve the outcome in patients with RA, JIA and possibly other inflammatory diseases.

\section{Author affiliations}

${ }^{1}$ Division of Rheumatology, Department of Medicine 3, Medical University of Vienna, Vienna, Austria

${ }^{2}$ 2nd Department of Medicine-Center for Rheumatic Disease, Hietzing Hospital, Vienna, Austria

${ }^{3}$ Laboratory of Immune Regulation, Wakayama Medical University, Wakayama, Japan
${ }^{4}$ Department of Rheumatology, Leiden University Medical Center, Leiden, The Netherlands

${ }^{5}$ Department of Rheumatology and Clinical Immunology, Charité, Free University and Humboldt University, Berlin, Germany

${ }^{6}$ Department of Rheumatology, Cochin Hospital, René Descartes University, Paris, France

${ }^{7}$ Academic Unit of Musculoskeletal Diseases, Leeds University, Leeds, UK

${ }^{8}$ Division of Rheumatology and Internal Medicine-CIC, Catholic University of the Sacred Heart-School of Medicine, Rome, Italy

${ }^{9}$ Division of Rheumatology, University Hospital, University of Geneva, Geneva, Switzerland

${ }^{10}$ Hospital for Special Surgery, Weill Medical College of Cornell University, New York,

New York, USA

${ }^{11}$ Hospital Clinic Universitario de Santiago, Santiago de Compostela, Spain

${ }^{12}$ Musculoskeletal Unit, Menzies Research Institute, University of Tasmania, Hobart,

Australia

${ }^{13}$ Department of Rheumatology, Diakonhjemmet Hospital, Oslo, Norway 
${ }^{14}$ Neil Betteridge Associates, London, UK

${ }^{15}$ Division of Rheumatology and Allergy and Clinical Immunology, Johns Hopkins University, Baltimore, Maryland, USA

${ }^{16}$ Institute of Infection and Immunity, Cardiff University School of Medicine, Cardiff, United Kingdom

${ }^{17}$ Department of Rheumatology, University of Montpellier, Montpellier, France

${ }^{18}$ Division of Rheumatology, University of Genova, Genova, Italy

${ }^{19}$ Division of Rheumatology, Department of Medicine, Medical University of Graz, Graz, Austria

${ }^{20}$ Aragon Health Research Institute, University Hospital Lozano Blesa, University of Zaragoza School of Medicine, Zaragoza, Spain

${ }^{21}$ Servicio de Reumatología, Hospital Universitario La Paz, Universidad Autónoma de Madrid, Madrid, Spain

${ }^{22}$ Division of Rheumatology, Policlinico S. Matteo, University of Pavia, Pavia, Italy

${ }^{23}$ Department of Rheumatology, Copenhagen University Hospital at Glostrup, Copenhagen, Denmark

${ }^{24}$ Institute of Rheumatology and Clinics of Rheumatology, Charles University, Prague, Czech Republic

${ }^{25}$ Department of Internal Medicine I, University of Cologne, Cologne, Germany

${ }^{26}$ Glasgow Cardiovascular Research Center, University of Glasgow, Glasgow, UK

${ }^{27}$ EULAR Standing Committee of People with Arthritis/Rheumatism in Europe, Zurich,

Switzerland

${ }^{28} 1$ st Department of Internal Medicine, University of Occupational and Environmental Health, Kitakyushu, Japan

${ }^{29}$ Division of Gastroenterology and Hepatology, Department of Medicine 3, Medical University of Vienna, Vienna, Austria

${ }^{30}$ Department of Internal Medicine, University of Naples, Rheumatology Unit, Naples, Italy

${ }^{31}$ Division of Infectious Diseases, Oregon Health and Science University, Portland, Oregon, USA

${ }^{32}$ Department Medical Humanities, VU Medical Centre, Amsterdam, The Netherlands

Correction notice This article has been corrected since it was published Online First. The author name Clifton Binghamlll has been amended to read Clifton 0 Bingham III.

Contributors JSS was the convenor of the consensus finding activity. All authors were members of the task force and contributed to the presented consensus statement, and all authors contributed to and agreed on the current manuscript.

Funding This activity was supported by a grant from Roche. No representative of the company was present at any of the consensus finding meetings, but representatives were available by telephone to address questions by the task force on insufficiently clear data, especially related to safety aspects, that might have occurred, or provide preprints of manuscripts or abstracts that have not yet been published.

Competing interests JSS received grant support from and has participated at advisory board meetings and symposia organised by Roche/Chugai/Genentech, BMS Janssen, Sanofi and UCB; GB has been a consultant and speaker for Roche and BMS and has received grant support from Roche, BMS and Sanofi; MD received grant support from and has participated at advisory board meetings and symposia organised by Roche; PE has provided expert advice for Roche, BMS, Lilly, Sanofi and undertaken clinical trials for Roche and BMS; GFF has received speaking fees and research grants from Roche; CG received consultant / speakers fees from Roche and BMS; AG has been a consultant and speaker for Roche/Genentech and holds shares of BMS; JJGR received grant support from and has participated at advisory board meetings and symposia organised by Roche; GJ has received grant support given talks and served on advisory boards for Roche; TKK received grant support from and/ or has participated at advisory board meetings and/or symposia organised by Roche, BMS, UCB; NN has received speaking, consulting fees and/or research grants from Chugai/Roche and BMS; NB's company has received income for services delivered to Roche; CB has been consultant and investigator for Roche/Genentech; VB has been a consultant for Roche/Genentech; EC has received research grants and served as a member of advisory boards and speakers bureau Roche/Chugai; BC had speaking engagements and served as consultant to Roche, BMS and UCB; AL is an advisor to Roche; MC received grants from BMS; WG has participated in advisory board meetings and speaking engagements and has received travel grants from Roche, BMS and UCB; NS received grant support from, consulted and had speaking engagements for Roche; EMM gave expert advice to Roche, BMS and UCB; ARR has been consultant and speaker for Roche/Chugai; YT has received speaking, consulting fees and/or research grants from Chugai, BMS and Janssen; GV participated in advisory board of Roche; KW served as consultant for Genentech; MdW has received honoraria from Roche; DvdH: Consulting and/or speaking activities for and/or research grants from Roche/Chugai, BMS, Sanofi and Aventis; director of Imaging Rheumatology bv. All other authors declare no conflict.

Provenance and peer review Not commissioned; externally peer reviewed.
Open Access This is an Open Access article distributed in accordance with the Creative Commons Attribution Non Commercial (CC BY-NC 3.0) license, which permits others to distribute, remix, adapt, build upon this work non-commercially, and license their derivative works on different terms, provided the original work is properly cited and the use is non-commercial. See: http://creativecommons.org/licenses/by-nc/3.0/

\section{REFERENCES}

1. Weinblatt ME. Efficacy of methotrexate in rheumatoid arthritis. $B r J$ Rheumatol 1995;34(Suppl 2):43-8.

2. Visser K, van der Heijde D. Optimal dosage and route of administration of methotrexate in rheumatoid arthritis: a systematic review of the literature. Ann Rheum Dis 2009;68:1094-9.

3. Smolen JS, Kalden JR, Scott DL, et al. Efficacy and safety of leflunomide compared with placebo and sulphasalazine in active rheumatoid arthritis: a double-blind, randomised, multicentre trial. Lancet 1999:353:259-66.

4. Emery $\mathbf{P}$, Breedveld FC, Lemmel EM, et al. A comparison of the efficacy and safety of leflunomide and methotrexate for the treatment of rheumatoid arthritis. Rheumatology 2000;39:655-65.

5. Elliott MJ, Maini RN, Feldmann M, et al. Randomised double-blind comparison of chimeric monoclonal antibody to tumour necrosis factor alpha (cA2) versus placebo in rheumatoid arthritis. Lancet 1994:344:1105-10.

6. Weinblatt ME, Kremer JM, Bankhurst AD, et al. A trial of etanercept, a recombinant tumor necrosis factor receptor:Fc fusion protein, in patients with rheumatoid arthritis receiving methotrexate. N Engl J Med 1999:340:253-9.

7. Genovese MC, Becker JC, Schiff M, et al. Abatacept for rheumatoid arthritis refractory to tumor necrosis factor alpha inhibition. N Engl J Med 2005;353:1114-23.

8. Emery P, Fleischmann R, Filipowicz-Sosnowska A, et al. The efficacy and safety of rituximab in patients with active rheumatoid arthritis despite methotrexate treatment: results of a phase IIB randomized, double-blind, placebo-controlled, dose-ranging trial. Arthritis Rheum 2006;54:1390-400.

9. Nam JL, Winthrop KL, van Vollenhoven RF, et al. Current evidence for the management of rheumatoid arthritis with biological disease-modifying antirheumatic drugs: a systematic literature review informing the EULAR recommendations for the management of RA. Ann Rheum Dis 2010;69: 976-86.

10. Smolen JS, Aletaha D, Koeller M, et al. New therapies for the treatment of rheumatoid arthritis. Lancet 2007;370:1861-74.

11. Singh JA, Christensen R, Wells GA, et al. Biologics for rheumatoid arthritis: an overview of Cochrane reviews. Cochrane Database Syst Rev 2009;(4):CD007848.

12. Schoels M, Aletaha D, Smolen JS, et al. Comparative effectiveness and safety of biological treatment options after tumour necrosis factor alpha inhibitor failure in rheumatoid arthritis: systematic review and indirect pairwise meta-analysis. Ann Rheum Dis 2012;71:1303-8.

13. Singh JA, Furst DE, Bharat A, et al. 2012 update of the 2008 american college of rheumatology recommendations for the use of disease-modifying antirheumatic drugs and biologic agents in the treatment of rheumatoid arthritis. Arthritis Care Res 2012;64:625-39.

14. Smolen JS, Landewe R, Breedveld FC, et al. EULAR recommendations for the management of rheumatoid arthritis with synthetic and biological disease-modifying antirheumatic drugs. Ann Rheum Dis 2010;69:964-75.

15. Furst DE, Keystone EC, Braun J, et al. Updated consensus statement on biological agents for the treatment of rheumatic diseases, 2010. Ann Rheum Dis 2011;70 (Suppl 1):i2-36.

16. Buch MH, Smolen JS, Betteridge N, et al. Updated consensus statement on the use of rituximab in patients with rheumatoid arthritis. Ann Rheum Dis 2011;70:909-20.

17. Hsu B, Sheng S, Smolen J, et al. Results from a 2-Part, proof-of-concept, dose-ranging, randomized, double-blind, placebo-controlled, phase 2 study of sirukumab, a human anti-interleukin-6 monoclonal antibody, in active rheumatoid arthritis patients despite methotrexate therapy. Arthritis Rheum 2011;63(Suppl):S1034.

18. Hickling M, Golor G, Juillon A, et al. Safety and pharmacokinetics of CDP6038, an anti-IL-6 monoclonal antibody, administered by subcutaneous injection and intravenous infusion to healthy male volunteers: a phase 1 study. Ann Rheum Dis 2011;70(Suppl 3):471.

19. Mease P, Strand V, Shalamberidze L, et al. A phase II, double-blind, randomised, placebo-controlled study of BMS945429 (ALD518) in patients with rheumatoid arthritis with an inadequate response to methotrexate. Ann Rheum Dis 2012; 71:1183-9.

20. Radin A, Mellis S, Jasson M, et al. Safety and effects on markers of inflammation of subcutaneously administered regn88/sar153191 (regn88), an interleukin-6 receptor inhibitor, in patients with rheumatoid arthritis: findings from phase 1 studies. Ann Rheum Dis 2010;69(Suppl 3):99.

21. Schoels MM, van der Heijde D, Breedveld FC, et al. Blocking the effects of Interleukin-6 in rheumatoid arthritis and other inflammatory rheumatic diseases-a systematic literature review and meta-analysis informing a consensus statement. Submitted 2012 
22. Oxford Centre for Evidence-based Medicine. Levels of Evidence (March 2009). http://www.cebm.net/index.aspx?0=1025 (Page last edited: 29 March 2012) (accessed 29 Apr 2012)

23. Kishimoto T. IL-6: from its discovery to clinical applications. Int Immunol 2010;22:347-52.

24. Naka T, Nishimoto N, Kishimoto T. The paradigm of IL-6: from basic science to medicine. Arthritis Res 2002;4(Suppl 3):S233-42.

25. Rose-John S, Scheller J, Elson G, et al. Interleukin-6 biology is coordinated by membrane-bound and soluble receptors: role in inflammation and cancer. $J$ Leukoc Biol 2006;80:227-36.

26. Jones SA. Directing transition from innate to acquired immunity: defining a role for IL-6. J Immunol 2005:17:3463-8.

27. Redlich K, Smolen JS. Inflammatory bone loss: pathogenesis and therapeutic intervention. Nat Rev Drug Discov 2012;11:234-50.

28. Mihara $\mathbf{M}$, Kotoh $\mathbf{M}$, Nishimoto $\mathrm{N}$, et al. Humanized antibody to human interleukin-6 receptor inhibits the development of collagen arthritis in cynomolgus monkeys. Clin Immunol 2001;98:319-26.

29. Nishimoto N, Kishimoto T, Yoshizaki K. Anti-interleukin 6 receptor antibody treatment in rheumatic disease. Ann Rheum Dis 2000;59(Suppl 1):i21-7.

30. Nishimoto N, Kanakura Y, Aozasa K, et al. Humanized anti-interleukin-6 receptor antibody treatment of multicentric Castleman disease. Blood 2005;106:2627-32.

31. Nishimoto N, Yoshizaki K, Maeda K, et al. Toxicity, pharmacokinetics, and dose-finding study of repetitive treatment with the humanized anti-interleukin 6 receptor antibody MRA in rheumatoid arthritis. Phase $1 / /$ clinical study. $J$ Rheumatol 2003;30:1426-35.

32. Choy EH, Isenberg DA, Garrood T, et al. Therapeutic benefit of blocking interleukin-6 activity with an anti- interleukin-6 receptor monoclonal antibody in rheumatoid arthritis: a randomized, double-blind, placebo-controlled, dose-escalation trial. Arthritis Rheum 2002;46:3143-50.

33. Maini RN, Taylor PC, Szechinski J, et al. Double-blind randomized controlled clinical trial of the interleukin-6 receptor antagonist, tocilizumab, in European patients with rheumatoid arthritis who had an incomplete response to methotrexate. Arthritis Rheum 2006;54:2817-29.

34. Nishimoto N, Yoshizaki K, Miyasaka N, et al. Treatment of rheumatoid arthritis with humanized anti-interleukin-6 receptor antibody: a multicenter, double-blind, placebo-controlled trial. Arthritis Rheum 2004;50:1761-9.

35. Food and Drug Administration U. Actemra-Highlights of prescribing information. 2012

36. Felson DT, Anderson JJ, Boers M, et al. American College of Rheumatology preliminary definition of improvement in rheumatoid arthritis. Arthritis Rheum 1995; 38:727-35

37. Bakker MF, Jacobs JW, Verstappen SM, et al. Tight control in the treatment of rheumatoid arthritis: efficacy and feasibility. Ann Rheum Dis 2007;66(Suppl 3): iii56-60.

38. Smolen JS, Aletaha D. The assessment of disease activity in rheumatoid arthritis Clin Exp Rheumatol 2010;28(Suppl 59):S18-27.

39. Smolen JS, Aletaha D. Interleukin-6 receptor inhibition with tocilizumab and attainment of disease remission in rheumatoid arthritis: The role of acute-phase reactants. Arthritis Rheum 2011;63:43-52.

40. Smolen JS, Beaulieu A, Rubbert-Roth A, et al. Effect of interleukin-6 receptor inhibition with tocilizumab in patients with rheumatoid arthritis (OPTION study): a double-blind, placebo-controlled, randomised trial. Lancet 2008;371:987-97.

41. Genovese MC, McKay JD, Nasonov EL, et al. Interleukin-6 receptor inhibition with tocilizumab reduces disease activity in rheumatoid arthritis with inadequate response to disease-modifying antirheumatic drugs: the tocilizumab in combination with traditional disease-modifying antirheumatic drug therapy study. Arthritis Rheum 2008;58:2968-80.

42. Emery P, Keystone E, Tony HP, et al. IL-6 receptor inhibition with tocilizumab improves treatment outcomes in patients with rheumatoid arthritis refractory to anti-tumour necrosis factor biologicals: results from a 24-week multicentre randomised placebo-controlled trial. Ann Rheum Dis 2008;67:1516-23.

43. Yazici $\mathbf{Y}$, Curtis JR, Ince A, et al. Efficacy of tocilizumab in patients with moderate to severe active rheumatoid arthritis and a previous inadequate response to disease-modifying antirheumatic drugs: the ROSE study. Ann Rheum Dis 2012;71:198-205.

44. Kremer JM, Blanco R, Brzosko M, et al. Tocilizumab inhibits structural joint damage in rheumatoid arthritis patients with inadequate responses to methotrexate: results from the double-blind treatment phase of a randomized placebo-controlled trial of tocilizumab safety and prevention of structural joint damage at one year. Arthritis Rheum 2011;63:609-21.

45. Jones G, Sebba A, Gu J, et al. Comparison of tocilizumab monotherapy versus methotrexate monotherapy in patients with moderate to severe rheumatoid arthritis: the AMBITION study. Ann Rheum Dis 2010;69:88-96.

46. Dougados M, Kissel K, Sheeran T, et al. Adding tocilizumab or switching to tocilizumab monotherapy in methotrexate inadequate responders: 24-week symptomatic and structural results of a 2-year randomised controlled strategy tria in rheumatoid arthritis (ACT-RAY). Ann Rheum Dis 2012; (Epub ahead of print).
47. Dougados M, Kissel K, Conaghan $\mathrm{P}$, et al. Clinical, radiographic and immunogenic effects after 1 year of tocilizumab (TCZ)-based treatment strategy with and without methotrexate (MTX) in RA: the ACT-RAY study. Ann Rheum Dis 2012;71(Suppl 3):185.

48. Nishimoto N, Miyasaka N, Yamamoto K, et al. Study of active controlled tocilizumab monotherapy for rheumatoid arthritis patients with an inadequate response to methotrexate (SATORI): significant reduction in disease activity and serum vascular endothelial growth factor by IL-6 receptor inhibition therapy. Mod Rheumatol 2009;19:12-19.

49. Gabay DC, Emery P, van Vollenhoven R, et al. Tocilizumab (TCZ) monotherapy is superior to adalimumab (ADA) monotherapy in reducing disease activity in patients with rheumatoid arthritis (ra): 24-week data from the phase 4 ADACTA trial. Ann Rheum Dis 2012;71(Suppl 3):152.

50. Nishimoto N, Hashimoto J, Miyasaka N, et al. Study of active controlled monotherapy used for rheumatoid arthritis, an IL-6 inhibitor (SAMURAI): evidence of clinical and radiographic benefit from an $\mathrm{x}$ ray reader-blinded randomised controlled trial of tocilizumab. Ann Rheum Dis 2007;66:1162-7.

51. Huizinga T, Kivitz AJ, Rell-Bakalarska M, et al. Sarilumab for the treatment of moderate-to-severe rheumatoid arthritis: results of a phase 2, randomized, double-blind placebo-controlled, international study. Ann Rheum Dis 2012;71(Suppl 3):60.

52. Burmester GR, Feist $\mathrm{E}$, Kellner $\mathrm{H}$, et al. Effectiveness and safety of the interleukin 6-receptor antagonist tocilizumab after 4 and 24 weeks in patients with active rheumatoid arthritis: the first phase Illb real-life study (TAMARA). Ann Rheum Dis 2011;70:755-9.

53. Breedveld FC, Weisman MH, Kavanaugh AF, et al. The PREMIER study - a multicenter, randomized, double-blind clinical trial of combination therapy with adalimumab plus methotrexate versus methotrexate alone or adalimumab alone in patients with early, aggressive rheumatoid arthritis who had not had previous methotrexate treatment. Arthritis Rheum 2006;54:26-37.

54. Curtis JR, Ogale S, Devenport J, et al. Effects of tocilizumab (TCZ) dose escalation on disease activity in adult RA patients (pts) with inadequate response at 16 weeks. Ann Rheum Dis 2011;70(Suppl 3):721.

55. European Medicines Agency. RoActemra-Summary of product characteristics. (accessed 29 Apr 2012). 2009 http://www.ema.europa.eu/docs/en GB/ document_library/EPAR___Product_Information/human/000955/WC500054890.pdf.

56. Smolen JS, Avila JC, Âletaha D. Tocilizumab inhibits progression of joint damage in rheumatoid arthritis irrespective of its anti-inflammatory effects: disassociation of the link between inflammation and destruction. Ann Rheum Dis 2012; 71:687-93

57. Jones G, Ding C. Tocilizumab: a review of its safety and efficacy in rheumatoid arthritis. Clin Med Insights Arthritis Musculoskelet Disord 2010;3:81-9.

58. Nemeth E, Rivera S, Gabayan V, et al. IL-6 mediates hypoferremia of inflammation by inducing the synthesis of the iron regulatory hormone hepcidin. $J$ Clin Invest 2004;113:1271-6.

59. Smolen JS, Aletaha D, Bijlsma JW, et al. Treating rheumatoid arthritis to target: recommendations of an international task force. Ann Rheum Dis 2010;69: 631-7.

60. Criswell LA, Such CL, Yelin EH. Differences in the use of second-line agents and prednisone for treatment of rheumatoid arthritis by rheumatologists and non-rheumatologists. J Rheumatol 1997;24:2283-90.

61. Solomon DH, Bates DW, Panush RS, et al. Costs, outcomes, and patient satisfaction by provider type for patients with rheumatic and musculoskeleta conditions: a critical review of the literature and proposed methodologic standards. Ann Intern Med 1997; 127:52-60.

62. Aletaha D, Smolen JS. The Definition and Measurement of Disease Modification in Inflammatory Rheumatic Diseases. Rheum Dis Clin North Am 2006;32:9-44.

63. Bykerk VP, Ostor AJ, Alvaro-Gracia J, et al. Tocilizumab in patients with active rheumatoid arthritis and inadequate responses to DMARDs and/or TNF inhibitors: a large, open-label study close to clinical practice. Ann Rheum Dis 2012;71:1950-4.

64. Lang VR, Englbrecht $\mathrm{M}$, Rech J, et al. Risk of infections in rheumatoid arthritis patients treated with tocilizumab. Rheumatology (Oxford) 2012;51:852-7.

65. Leffers HC, Ostergaard M, Glintborg B, et al. Efficacy of abatacept and tocilizumab in patients with rheumatoid arthritis treated in clinical practice: results from the nationwide Danish DANBI0 registry. Ann Rheum Dis 2011;70:1216-22.

66. van Assen S, Agmon-Levin N, Elkayam 0, et al. EULAR recommendations for vaccination in adult patients with autoimmune inflammatory rheumatic diseases. Ann Rheum Dis 2011;70:414-22.

67. Gout T, Ostor AJ, Nisar MK. Lower gastrointestinal perforation in rheumatoid arthritis patients treated with conventional DMARDs or tocilizumab: a systematic literature review. Clin Rheumatol 2011;30:1471-4.

68. Curtis JR, Lanas A, John A, et al. Factors associated with gastrointestinal perforation in a cohort of patients with rheumatoid arthritis. Arthritis Care Res 2012;doi:10.1002/acr.21764

69. Nagashima T, Minota S. Long-term tocilizumab therapy in a patient with rheumatoid arthritis and chronic hepatitis B. Rheumatology (Oxford) 2008;47:1838-40. 
70. Nagashima T, Maruyama A, Kamata $Y$, et al. Unchanged serum viral load and liver function during tocilizumab treatment in a patient with rheumatoid arthritis and hepatitis C virus infection. Rheumatol Int 2011;32:2231-2.

71. Tsuboi H, Tsujii A, Nampei A, et al. A patient with rheumatoid arthritis treated with tocilizumab together with lamivudine prophylaxis after remission of infliximab-reactivated hepatitis B. Mod Rheumatol 2011;21:701-5.

72. Carroll MB. The impact of biologic response modifiers on hepatitis B virus infection. Expert Opin Biol Ther 2011;11:533-44.

73. Koike T, Harigai M, Inokuma S, et al. Postmarketing surveillance of tocilizumab for rheumatoid arthritis in Japan: interim analysis of 3881 patients. Ann Rheum Dis 2011;70:2148-51.

74. Carroll MB, Forgione MA. Use of tumor necrosis factor alpha inhibitors in hepatitis B surface antigen-positive patients: a literature review and potential mechanisms of action. Clin Rheumatol 2010;29:1021-9.

75. Hamaki T, Kami M, Kusumi E, et al. Prophylaxis of hepatitis B reactivation using lamivudine in a patient receiving rituximab. Am J Hematol 2001:68:292-4.

76. Winthrop KL, Calabrese LH. Let the fog be lifted: screening for hepatitis B virus before biological therapy. Ann Rheum Dis 2011;70:1701-3.

77. Germanidis G, Hytiroglou P, Zakalka M, et al. Reactivation of occult hepatitis B virus infection, following treatment of refractory rheumatoid arthritis with abatacept. J Hepatol 2012;56:1420-1.

78. Saunders BM, Frank AA, Orme IM, et al. Interleukin-6 induces early gamma interferon production in the infected lung but is not required for generation of specific immunity to Mycobacterium tuberculosis infection. Infect Immun 2000:68:3322-6.

79. Rubbert-Roth A. Assessing the safety of biologic agents in patients with rheumatoid arthritis. Rheumatology (Oxford) 2012;51(Suppl 5):v38-47.

80. Ishikawa T, Kojima T, Kanamono T, et al. Pregnancy in women with rheumatoid arthritis receiving biologic agents-results from 7 years of surveillance of clinical practice in Japanese TBC registry for the patients with rheumatoid arthritis using biologics. Ann Rheum Dis 2011;70(Suppl 3):256.

81. Rubbert-Roth A, Goupille PM, Moosavi S, et al. First Experiences with Pregnancies in RA Patients (pts) Receiving Tocilizumab (TCZ) Therapy. Arthritis Rheum 2010;62(Suppl):S161.

82. Genovese MC, Beaulieu AD, Ramos-Remus $C$, et al. Efficacy of tocilizumab in combination with DMARDs is superior to DMARDs alone in moderate-to-severe rheumatoid arthritis based on ACR criteria: a pooled analysis of clinical trial data from OPTION and TOWARD. Ann Rheum Dis 2008;67(Suppl II):195.

83. Imoto $\mathbf{N}$, Japanse MRA study group for RA. Drug free REmission after cessation of Actemra Monotherapy (DREAM study). Ann Rheum Dis 2010;69(Suppl 3):98

84. Felson DT, Smolen JS, Wells G, et al. American college of rheumatology/european league against rheumatism provisional definition of remission in rheumatoid arthritis for clinical trials. Ann Rheum Dis 2011;70:404-13.

85. Diamantopoulos A, Benucci M, Capri S, et al. Economic evaluation of tocilizumab combination in the treatment of moderate-to-severe rheumatoid arthritis in Italy. J Med Econ 2012;15:576-85.

86. Soini EJ, Hallinen TA, Puolakka $K$, et al. Cost-effectiveness of adalimumab, etanercept, and tocilizumab as first-line treatments for moderate-to-severe rheumatoid arthritis. J Med Econ 2012;15:340-51.

87. Nishimoto N, Miyasaka N, Yamamoto K, et al. Long-term safety and efficacy of tocilizumab, an anti-IL-6 receptor monoclonal antibody, in monotherapy, in patients with rheumatoid arthritis (the STREAM study): evidence of safety and efficacy in a 5-year extension study. Ann Rheum Dis 2009;68:1580-4.

88. Schiff $\mathbf{M H}$, Kremer JM, Jahreis A, et al. Integrated safety in tocilizumab clinical trials. Arthritis Res Ther 2011;13:R141.

89. Ogata A, Hirano T, Hishitani Y, et al. Safety and efficacy of tocilizumab for the treatment of rheumatoid arthritis. Clin Med Insights Arthritis Musculoskelet Disord 2012:5:27-42.

90. Chauffier K, Salliot C, Berenbaum F, et al. Effect of biotherapies on fatigue in rheumatoid arthritis: a systematic review of the literature and meta-analysis. Rheumatology (Oxford) 2012:51:60-8.
91. Yokota S, Imagawa T, Mori M, et al. Efficacy and safety of tocilizumab in patients with systemic-onset juvenile idiopathic arthritis: a randomised, double-blind placebo-controlled, withdrawal phase III trial. Lancet 2008;371:998-1006.

92. Imagawa T, Yokota S, Mori M, et al. Safety and efficacy of tocilizumab, an anti-IL-6-receptor monoclonal antibody, in patients with polyarticular-course juvenile idiopathic arthritis. Mod Rheumatol 2012;22:109-15.

93. Okuda Y, Takasugi K. Successful use of a humanized anti-interleukin-6 receptor antibody, tocilizumab, to treat amyloid $A$ amyloidosis complicating juvenile idiopathic arthritis. Arthritis Rheum 2006;54:2997-3000.

94. Magro-Checa C, Navas-Parejo CA, Borrego-Garcia E, et al. Successful use of tocilizumab in a patient with nephrotic syndrome due to a rapidly progressing $A A$ amyloidosis secondary to latent tuberculosis. Amyloid 2011;18:235-9.

95. Hagihara K, Kawase I, Tanaka T, et al. Tocilizumab ameliorates clinical symptoms in polymyalgia rheumatica. J Rheumatol 2010;37:1075-6.

96. Salvarani C, Magnani L, Catanoso M, et al. Tocilizumab: a novel therapy for patients with large-vessel vasculitis. Rheumatology (Oxford) 2012;51: $151-6$.

97. Narazaki M, Hagihara K, Shima $Y$, et al. Therapeutic effect of tocilizumab on two patients with polymyositis. Rheumatology (Oxford) 2011;50:1344-6.

98. Illei GG, Shirota Y, Yarboro CH, et al. Tocilizumab in systemic lupus erythematosus: data on safety, preliminary efficacy, and impact on circulating plasma cells from an open-label phase I dosage-escalation study. Arthritis Rheum 2010;62: 542-52.

99. Shima Y, Kuwahara Y, Murota $H$, et al. The skin of patients with systemic sclerosis softened during the treatment with anti-IL-6 receptor antibody tocilizumab. Rheumatology (Oxford) 2010;49:2408-12.

100. Unizony S, Arias-Urdaneta L, Miloslavsky E, et al. Tocilizumab for the treatment of large-vessel vasculitis (giant cell arteritis, takayasu arteritis) and polymyalgia rheumatica. Arthritis Care Res (Hoboken) 2012:64:1720-9

101. Murakami M, Nishimoto N. The value of blocking IL-6 outside of rheumatoid arthritis: current perspective. Curr Opin Rheumatol 2011;23:273-7.

102. Liang B, Gardner DB, Griswold DE, et al. Anti-interleukin-6 monoclonal antibody inhibits autoimmune responses in a murine model of systemic lupus erythematosus. Immunology 2006;119:296-305.

103. Nishimoto N, Terao K, Mima T, et al. Mechanisms and pathologic significances in increase in serum interleukin-6 (IL-6) and soluble IL-6 receptor after administration of an anti-IL-6 receptor antibody, tocilizumab, in patients with rheumatoid arthritis and Castleman disease. Blood 2008;112:3959-64.

104. Harada N, Sayama K, Tanaka K, et al. (Long-term treatment with a humanized anti-interleukin-6 receptor antibody (tocilizumab), improving interstitial pneumonia in a patient with multicentric Castleman disease). Nihon Kokyuki Gakkai Zasshi 2010;48:145-50.

105. Del Castillo Pinol N, Gossec L, Sparsa L, et al. Tocilizumab for treatment of refractory spondyloarthritis: report of 5 patients. Ann Rheum Dis 2011;70(Suppl 3):343

106. Dudler J, Aubry-Rozier B. Tocilizumab in axial sponylarthropathies: about 18 cases Ann Rheum Dis 2011;70(Suppl 3):128.

107. Sieper J, Porter-Brown B, Thompson L, et al. Tocilizumab (TCZ) is not effective for the treatment of ankylosing spondylitis (AS): results of a phase 2, international, multicentre, randomised, double-blind, placebo-controlled trial. Ann Rheum Dis 2012;71(Suppl 3):110.

108. Sieper J, Inman RD, Badalamenti S, et al. Sarilumab for the treatment of ankylosing spondylitis: results of a phase 2, randomized. double-blind placebo-controlled, international study (ALIGN). Ann Rheum Dis 2012 $\mathbf{7 1}$ (Suppl 3):111

109. Ogata A, Umegaki N, Katayama I, et al. Psoriatic arthritis in two patients with an inadequate response to treatment with tocilizumab. Joint Bone Spine 2012:79:85-7.

110. Ito $\mathbf{H}$, Takazoe M, Fukuda $Y$, et al. A pilot randomized trial of a human anti-interleukin-6 receptor monoclonal antibody in active Crohn's disease. Gastroenterology 2004:126:989-96. 